\title{
Ion-specific Effect on Oil-in-water Emulsion Gels Containing a Stimuli-responsive Fibrous Assembly of Amidoamine-derivative Hydrogelator
}

\author{
Clara Morita-Imura $^{1 *}$, Yoshiro Imura ${ }^{2}$ and Takeshi Kawai ${ }^{2 *}$ \\ ${ }^{1}$ Department of Applied Chemistry, Faculty of Science, Chuo University (1-13-27 Kasuga, Bunkyo-ku, Tokyo 112-8551, JAPAN) \\ ${ }^{2}$ Department of Industrial Chemistry, Faculty of Engineering, Tokyo University of Science (1-3 Kagurazaka, Shinjuku-ku, Tokyo 162-8601, \\ JAPAN)
}

\begin{abstract}
Amidoamine derivative C18AA forms a highly viscous oil-in-water (O/W) emulsion, called an "emulsion gel." Previously, it was showed that the viscosity sensitively changes with the C18AA concentration, temperature, $\mathrm{pH}$ changes, and salt addition. In this work, $\mathrm{C} 18 \mathrm{AA}$ concentration in the continuous aqueous phase $\left([\mathrm{C} 18 \mathrm{AA}]_{\mathrm{w}}\right)$ was investigated at different compositions, and it was found that a threshold concentration value of $16.5 \mathrm{wt} \%$ was required to obtain a highly viscous emulsion gel below $45^{\circ} \mathrm{C}$. C18AA formed micellar networks in the aqueous phase, and stimuli or additives increase the value of $[\mathrm{C} 18 \mathrm{AA}]_{w}$, so that the C18AA micellar network could grow in the continuous aqueous phase.
\end{abstract}

Key words: emulsion, gel, surfactant, stimuli-responsive, salt

\section{INTRODUCTION}

The emulsification technique has been developed for use in the production of various materials such as medicines, cosmetics, paints, and foods ${ }^{1-4)}$. Generally, an emulsion is a thermodynamically unstable phase. In emulsions, drainage of the continuous phase occurs by external stimuli, or by gravity with time. This causes the neighboring emulsion droplets to coalesce, and demulsification is observed ${ }^{5,6)}$. To overcome the low stability of emulsions, viscous fluids or additives, e.g., silicone oil, polymer, $\alpha$-crystalline phase, and lyotropic liquid crystal $^{7-11)}$, have been used in the continuous phase of emulsions. The continuous phase of a non-Newtonian fluid is likely to inhibit the mobility of the emulsion droplets, drainage, and phase separation. These fluids are often classified as "emulsion gels" because of the high zero-shear viscosity originating from the property of the continuous phase.

The additives to the continuous phase also perform other functions in the emulsion. In particular, functional soft matters such as stimuli-responsive materials are used to introduce novel applications of emulsion systems. Aramaki et $a l .^{12-15)}$ reported emulsions with the continuous phase of lyotropic liquid crystals such as hexagonal $\mathrm{H}_{1}$ and $\mathrm{H}_{2}$ and cubic $\mathrm{I}_{1}$ and $\mathrm{I}_{2}$ phases, and discussed the effect on the viscosity of emulsions. Viscosity transitions of $\mathrm{O} / \mathrm{H}_{1}$ emulsion caused by changes in temperature has been to the phase transition of liquid crystals $^{12)}$. In other words, stimuli-responsive emulsions could be obtained by introducing suitable functional materials in the continuous phase, and the stimuli-responsiveness could be tuned by additives.

Previously, we investigated heat- ${ }^{16)}$ and pH-induced ${ }^{17)}$ toluene/water emulsion gels using an amidoamine derivative C18AA(Fig. 1a) as an emulsifier. The viscosity of the emulsion increased on heating. It also increased at $\mathrm{pH}$ values below 9.5, at which the terminal amines of C18AA protonate. We also demonstrated a heat-induced gelation phenomenon, which was effectively brought about by the high concentrations of C18AA and/or the addition of $\mathrm{LiCl}$. This unique gelation performance with stimuli-responsiveness was reported for the C18AA emulsion, but the detailed mechanism of the gelation was not discussed. In a subsequent study ${ }^{18)}$, we also reported the formation of elongated C18AA micelles involving strong intermolecular hydrogen bonding between amide moieties in aqueous phase. The micelles elongated with increasing C18AA concentration, and the emulsion showed viscosity transition because of the overlapping and entanglement of micellar fibrils. In the aqueous solution of C18AA, addition of $\mathrm{LiCl}$ also affected the micellar network by encouraging the hy-

\footnotetext{
*Correspondence to: Clara Morita-Imura, Department of Applied Chemistry, Faculty of Science, Chuo University, 1-13-27 Kasuga, Bunkyo-ku, Tokyo 112-8551, JAPAN; Takeshi Kawai, Department of Industrial Chemistry, Faculty of Engineering, Tokyo University of Science, 1-3 Kagurazaka, Shinjuku-ku, Tokyo 162-8601, JAPAN

E-mail: kawai@ci.kagu.tus.ac.jp

Accepted July 26, 2016 (received for review June 7, 2016)
}

Journal of Oleo Science ISSN 1345-8957 print / ISSN 1347-3352 online

http://www.jstage.jst.go.jp/browse/jos/ http://mc.manusriptcentral.com/jjocs 


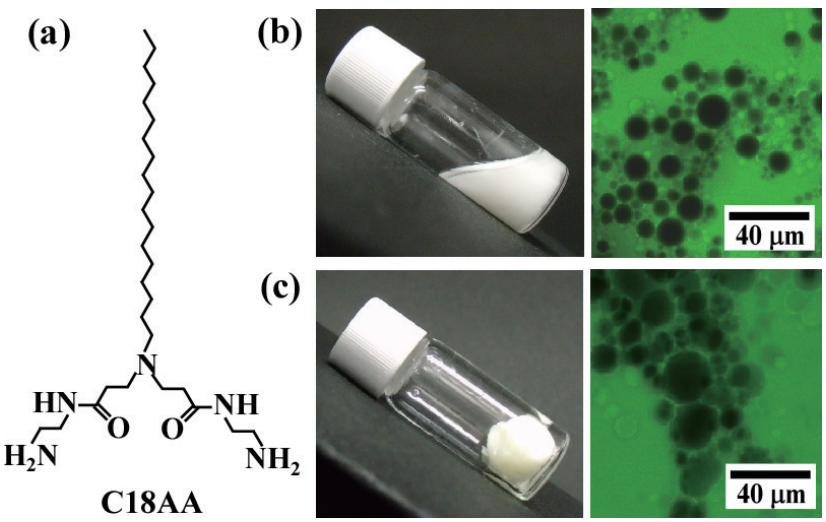

Fig. 1 (a) Molecular structure of C18AA. (b, c) Photographs and fluorescence optical micrographs using Rhodamine $6 \mathrm{G}$ of toluene/C18AA/water emulsions at $25^{\circ} \mathrm{C} \cdot[\mathrm{C} 18 \mathrm{AA}]=(\mathrm{b}) 15 \mathrm{wt} \%$, and $(\mathrm{c})$ 33 wt $\%$.

dration of amide moieties ${ }^{18)}$, which is often observed in amino-acid derivatives ${ }^{19)}$ or biopolymers ${ }^{20-24)}$. These insights into the C18AA aqueous solution provide a new hypothesis on the stimuli-responsive gelation of a C18AA toluene/water emulsion: C18AA micellar networks in the continuous aqueous phase bring about the viscosity transition of the emulsion. It is assumed that C18AA in a toluene/ water system is distributed to the aqueous phase on heating by the hydration of amides ${ }^{16)}$. To detect C18AA micellar networks in the emulsion gel, it is necessary to investigate how the C18AA concentration in the continuous aqueous phase $[\mathrm{C} 18 \mathrm{AA}]_{\mathrm{w}}$ changes the gelation behavior. In this work, we discussed the relation between $[\mathrm{C} 18 \mathrm{AA}]_{\mathrm{w}}$ and the emulsion viscosity. The study also focused on the ion-specific effect ${ }^{25)}$ (called the Hofmeister effect) to control C18AA distribution in the continuous aqueous phase by a promotive influence on hydration, and revealed the heat-induced gelation mechanism in toluene/C18AA/ water emulsions.

\section{EXPERIMENTAL PROCEDURES}

\subsection{Materials}

All chemicals were of reagent grade and obtained from Sigma-Aldrich Co. LLC or Kanto Chemicals Co. Inc. Commercially available reagents and solvents were used without further purification, except methyl acrylate (Kanto Chemicals), which was purified by distillation under reduced pressure in a nitrogen atmosphere, and octadecylamine, which was recrystallized twice from hexane.

\subsection{Synthesis of C18AA}

$N$-(2-amino-ethyl) -3- \{[2-(2-amino-ethylcarbamoyl) -ethyl]-octadecyl-amino\}-propioamide (C18AA) was syn- thesized according to a previously published procedure. First, $10.22 \mathrm{~g}$ ( $0.12 \mathrm{~mol})$ of methyl acrylate was added to 2.0 $\mathrm{g}(7.12 \mathrm{mmol})$ of octadecylamine in $15 \mathrm{~mL}$ of methanol. The solution was stirred at $40^{\circ} \mathrm{C}$ for 3 days, and then the solvent and excess methyl acrylate were removed from the solution by rotary evaporation. 3-[(2-Methoxycarbonyl-ethyl) -octadecyl-amino]-propionic acid methyl ester (C18ME) was obtained as a viscous liquid. Yield: $95 \%$.

${ }^{1} \mathrm{H}-\mathrm{NMR}\left(\mathrm{CDCl}_{3}\right): \delta 0.88\left(\mathrm{t}, 3 \mathrm{H}, \mathrm{CH}_{2} \mathbf{C H}_{3}\right), 1.25(\mathrm{br}, 28 \mathrm{H}$, $\left.\mathbf{C H}_{2}\right), 1.42\left(\mathrm{br}, 4 \mathrm{H}, \mathbf{C H}_{2} \mathrm{CH}_{3}, \mathrm{CH}_{2} \mathbf{C H}_{2} \mathrm{CH}_{2} \mathrm{~N}\right), 2.37(\mathrm{t}, 4 \mathrm{H}$, $\left.\mathrm{CH}_{2} \mathbf{C H}_{2} \mathrm{CO}\right), 2.43\left(\mathrm{t}, 2 \mathrm{H}, \mathbf{C H}_{2} \mathrm{~N}\right), 2.76\left(\mathrm{t}, 4 \mathrm{H}, \mathrm{NCH}_{2} \mathrm{CH}_{2} \mathrm{CO}\right)$, $3.66\left(\mathrm{~s}, 6 \mathrm{H}, \mathrm{OCH}_{3}\right)$. HRMS: calcd for $\mathrm{C} 18 \mathrm{ME}\left(\mathrm{M}+\mathrm{Na}^{+}\right)$ 464.37, found 464.38 .

Next, $3.2 \mathrm{~g}$ of C18ME and $17.8 \mathrm{~g}(0.30 \mathrm{~mol})$ of ethylenediamine were dissolved in $15 \mathrm{~mL}$ of methanol and the mixture was stirred for 1 week at room temperature. Upon removal of the solvent and ethylenediamine by evaporation and freeze-drying, C18AA was obtained as a light yellow solid. The final product was recrystallized from the crude solid using a mixed solvent of toluene and methanol. Yield: $90 \%$.

${ }^{1} \mathrm{H}-\mathrm{NMR}\left(\mathrm{CDCl}_{3}\right): \delta 0.88\left(\mathrm{t}, 3 \mathrm{H}, \mathrm{CH}_{2} \mathbf{C H}_{3}\right), 1.25(\mathrm{br}, 28 \mathrm{H}$, $\left.\mathbf{C H}_{2}\right), 1.45\left(\right.$ br, $\left.4 \mathrm{H}, \mathbf{C H}_{2} \mathrm{CH}_{3}, \mathrm{CH}_{2} \mathbf{C H}_{2} \mathrm{CH}_{2} \mathrm{~N}\right), 2.36(\mathrm{t}, 4 \mathrm{H}$, $\left.\mathrm{CH}_{2} \mathbf{C H}_{2} \mathrm{O}\right), 2.42\left(\mathrm{t}, 2 \mathrm{H}, \mathbf{C H}_{2} \mathrm{~N}\right), 2.73\left(\mathrm{t}, 4 \mathrm{H}, \mathrm{NCH}_{2} \mathrm{CH}_{2} \mathrm{CO}\right)$, $2.82\left(\mathrm{t}, 4 \mathrm{H}, \mathbf{C H}_{2} \mathrm{NH}_{2}\right), 3.29\left(\mathrm{q}, 4 \mathrm{H}, \mathrm{NHCH}_{2}\right)$. HRMS: calcd for $\mathrm{C} 18 \mathrm{AA}\left(\mathrm{M}+\mathrm{H}^{+}\right) 498.47$, found 498.48 .

$\mathrm{NMR}$ spectra were recorded in $\mathrm{CDCl}_{3}$ on a Bruker 400 Ultrashield spectrometer operating at $400 \mathrm{MHz}$.

\subsection{Preparation of toluene/C18AA/water emulsion}

A typical preparation of the toluene/C18AA/water emulsion was carried out as follows. First, $0.080 \mathrm{~mL}$ of a C18AA aqueous solution(A) was added to $0.100 \mathrm{~mL}$ of toluene, and the mixture was then vigorously stirred overnight. The C18AA concentration [C18AA] was initially defined as the concentration in the solution(A) and varied from $15 \mathrm{wt} \%$ to $35 \mathrm{wt} \%$. For gelation, inorganic salts were also added to the solution (A) with concentrations of $0-0.2 \mathrm{M}$.

\subsection{Characterization}

Rheological measurements were performed on a MARS rheometer (Thermo Scientific) with a parallel plate and a cone-plate with a diameter of $35 \mathrm{~mm}$ and a Peltier-based temperature control. Dynamic frequency sweeps were conducted within the linear viscoelastic regime of the emulsions. The samples were equilibrated for $5 \mathrm{~min}$ at each temperature reading prior to measurements. The rate of temperature increase was controlled at $3^{\circ} \mathrm{C} / \mathrm{min}$.

To determine the distribution of C18AA in the continuous aqueous phase, we measured the distribution coefficient of C18AA in the toluene/water system. The emulsion was prepared by mixing $50 \mathrm{~mL}$ of toluene and $50 \mathrm{~mL}$ of a 13 wt\% C18AA aqueous solution (under the conditions of $[\mathrm{LiCl}]=0$ and $0.1 \mathrm{M},[\mathrm{NaCl}]=0.1 \mathrm{M}$, and $[\mathrm{KCl}]=0.1 \mathrm{M})$. 
The emulsion was then subjected to creaming at a given temperature, and a sample of the clear aqueous phase in the bottom layer was pipetted out to measure the solubility of C18AA in it. The water was removed by freeze-drying the sample in vacuum and the residual C18AA weight was determined by subtracting the weight of additional salts. Finally, the distribution coefficient for C18AA molecules in the aqueous phase, $\phi_{\mathrm{w}}$, was determined based on this weight.

\section{RESULTS AND DISCUSSION}

\subsection{Effect of C18AA concentration on the viscosity of toluene/C18AA/water emulsion}

The toluene/C18AA/water emulsions were prepared with an inner phase ratio of 0.55 , regardless of the C18AA concentration. The ratio was sufficiently high, but the emulsions were not classified as high-inner-phase emulsions ${ }^{26,27)}$. At $[\mathrm{C} 18 \mathrm{AA}]=15 \mathrm{wt} \%$ (Fig. 1b), the C18AA emulsion behaved as a conventional Newtonian fluid and had a zeroshear viscosity of $0.01 \mathrm{~Pa} \cdot \mathrm{s}(\text { Fig. 2a })^{28)}$.

Increasing the $\mathrm{C} 18 \mathrm{AA}$ concentration increased the emulsion viscosity. Above $[\mathrm{C} 18 \mathrm{AA}]=33 \mathrm{wt} \%$ (Fig. 1c), the emulsion reached a gel-like state (yield stress $\tau_{y}=64 \mathrm{~Pa}$ ). Steady shear viscosity measurements showed a shear-thinning behavior that suggested a gel property at low shear rate conditions (Fig. 2a). Oscillatory rheological measurements also showed gel-like behavior and the elastic modulus of $G$ ' was slightly higher than the viscous modulus $G$ " at a wide range of frequency in $33 \mathrm{wt} \%$ emulsion, compared to that in 15 wt\% emulsion(Fig. 2b). The 33 wt\% C18AA emulsion gel did not phase-separate for a long time period (about a month), though the $15 \mathrm{wt} \%$ C18AA emulsion separated into aqueous and toluene phases within a day.

As mentioned above, the $33 \mathrm{wt} \%$ C18AA emulsion gel had sufficient spaces in the continuous phase (Fig. 1b). It (a)

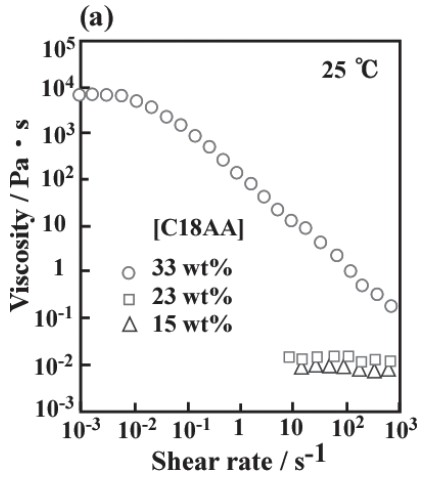

(b)

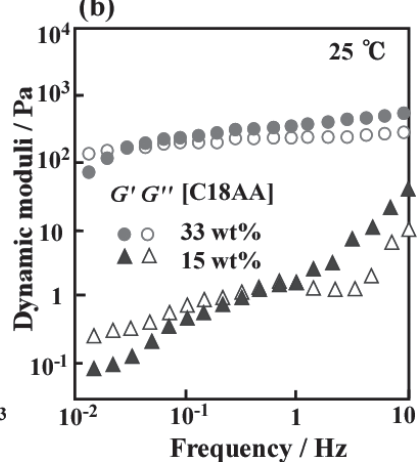

Fig. 2 (a) Steady shear viscosity and (b) dynamic rheology of toluene/C18AA/water emulsion at $25^{\circ} \mathrm{C}$ for various $[\mathrm{C} 18 \mathrm{AA}]$ values.

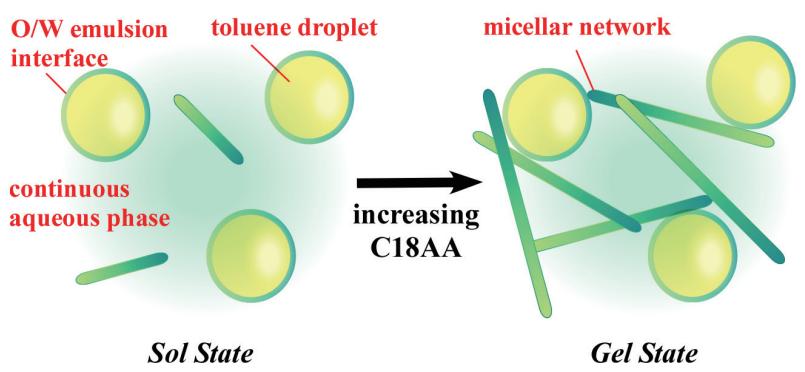

Scheme 1 Gelation of C18AA-concentrated emulsion.

seemed that the gelation occurred not by the coagulation of droplets, as in a high-inner-phase-ratio emulsion gel, but because of another network in the continuous aqueous phase. The distribution of C18AA was determined for the toluene/water system at room temperature. It was found that $40 \%$ of C18AA was distributed in the aqueous phase, i.e., C18AA concentration in the continuous phase, $[\mathrm{C} 18 \mathrm{AA}]_{\mathrm{w}}$, was estimated to $16.5 \mathrm{wt} \%$ for the $33 \mathrm{wt} \%$ -C18AA emulsion gel. This concentration(i.e., $16.5 \mathrm{wt} \%$ ) was nearly equal to the overlap concentration of elongated C18AA micelles in the aqueous solution ${ }^{18)}$. Thus, the increase in C18AA concentration, which induced micellar elongation and formation of a micellar network, was a driving force for the gelation of the C18AA emulsion (Scheme 1).

\subsection{Variation of C18AA distribution in the continuous aqueous phase with heating}

The C18AA distribution ratio was affected by external stimuli such as temperature. Elevating the temperature increased the C18AA distribution in the aqueous phase. For the $23 \mathrm{wt} \%$-C18AA emulsion, [C18AA] increased from 11 wt $\%$ (at $25^{\circ} \mathrm{C}$ ) to $13 \mathrm{wt} \%\left(\right.$ at $55^{\circ} \mathrm{C}$ ) on heating. At the same time, the zero-shear viscosity of the emulsion (Fig. 3a) slightly increased from $0.01 \mathrm{~Pa} \cdot \mathrm{s}\left(\right.$ at $25^{\circ} \mathrm{C}$ ) to $12 \mathrm{~Pa} \cdot \mathrm{s}$ (at $55^{\circ} \mathrm{C}$ ), though the emulsion remained a fluid and did not
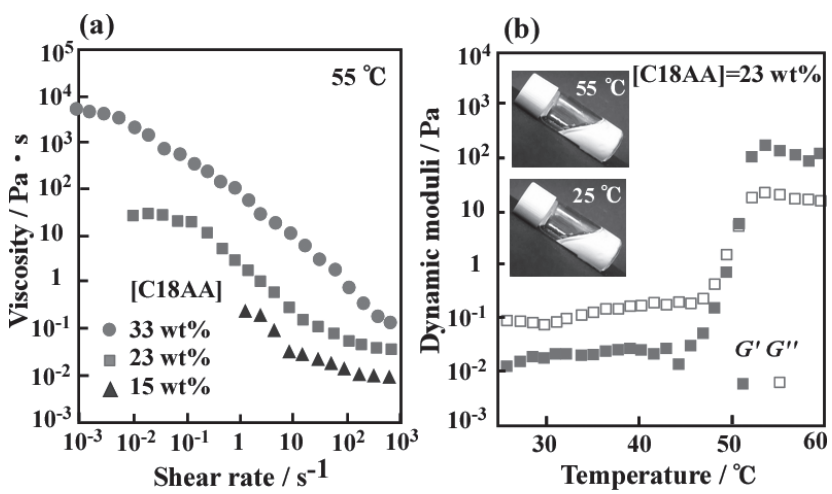

Fig. 3 (a) Steady shear viscosity at $55^{\circ} \mathrm{C}$ and (b) temperature dependence of dynamic modulus at an oscillatory frequency of $1 \mathrm{~Hz}$ of toluene/C18AA/ water emulsion. 
turn into a "gel" (Fig. 3b). This insufficient viscosity transition on heating was due to a small increase in $[\mathrm{C} 18 \mathrm{AA}]_{\mathrm{w}}$ at the higher temperature.

\subsection{Controlling the heat-induced gelation of C18AA emul- sion by salt addition}

In our previous studies, the heat-induced hydration of C18AA amide moieties was significantly promoted by the addition of $\mathrm{LiCl}^{16,18)}$ without a change in the micellar morphology ${ }^{18)}$. To achieve the heat-induced gelation of the C18AA emulsion, increasing $[\mathrm{C} 18 \mathrm{AA}]_{\mathrm{w}}$ on heating via hydration seemed to be effective, and therefore, we attempted the addition of salts in the aqueous phase of the emulsion. Generally, the Hofmeister series is useful for the control of the solvation of proteins ${ }^{25}$. The series reports the order $\mathrm{Cl}^{-} \sim \mathrm{Br}^{-}>\mathrm{SO}_{4}{ }^{2-}>\mathrm{CO}_{3}{ }^{2-}$ for anions exhibiting a salting-in effect, and the order $\mathrm{Li}^{+}>\mathrm{Na}^{+}>\mathrm{K}^{+}$for cations.

Emulsions were prepared with $[\mathrm{C} 18 \mathrm{AA}]=23 \mathrm{wt} \%$ and varying concentrations of aqueous salt solutions, and they were compared in terms of heat-induced gelation properties. In the absence of salt, the viscosity transition temperature was $\sim 52^{\circ} \mathrm{C}$, which was determined as the crossover point of $G^{\prime}$ and $G^{\prime \prime}$ (Fig. 3b). Among the emulsions with sodium salts (Fig. 4a), the transition temperature was barely affected by carbonate and sulfate but decreased drastically because of the presence of bromide and chloride. In the case of chlorides (Fig. $4 \mathrm{~b}$ ), the transition temperature shifted further in the presence of bigger cations such as $\mathrm{Li}^{+}$in LiCl. These results agreed well with the salting-in effect predicted by the Hofmeister series. The emulsions with chlorides were seen to transit to "gelled" emulsions with high elastic moduli $G$ ', especially with $\mathrm{LiCl}$, with reduced fluidity (Fig. 5). This meant that the salting-in effect of chlorides was effective against the gelation of the C18AA emulsion, i.e., the viscosity transition was closely related to the hydration of C18AA. (a)

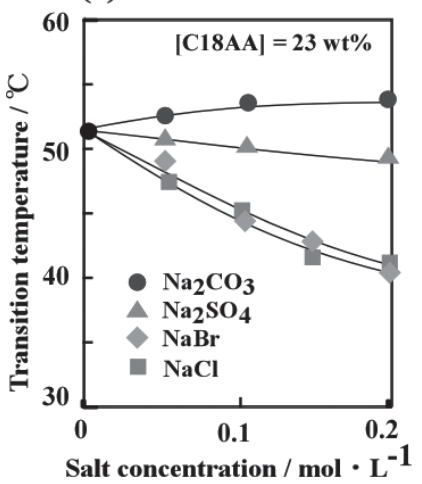

(b)

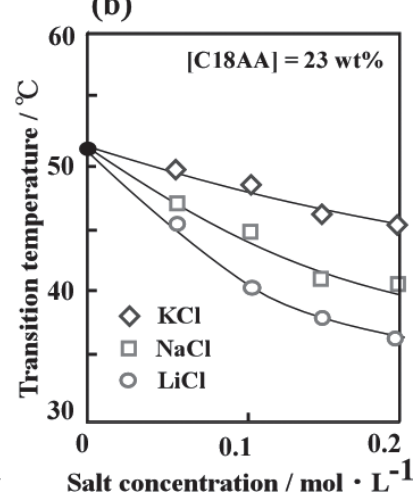

Fig. 4 Viscosity transition temperature of toluene/C18AA/ water emulsion with (a) sodium salts and (b) chlorides. $[\mathrm{C} 18 \mathrm{AA}]=23 \mathrm{wt} \%$. (a)

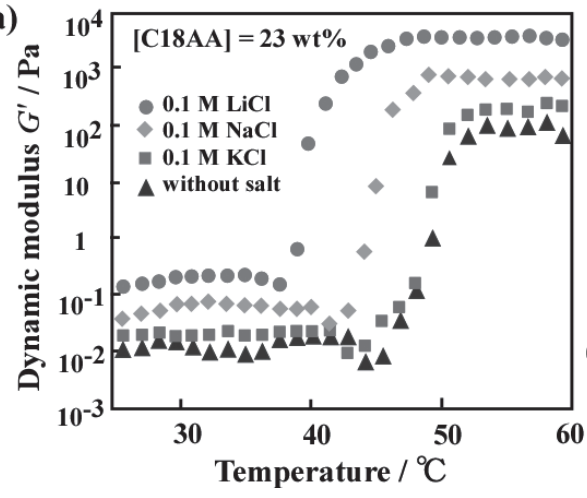

(b)

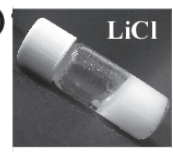

(c)

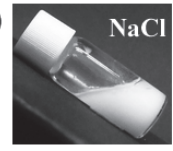

(d)

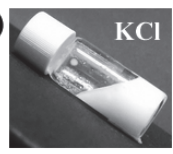

Fig. 5 (a) Temperature dependence of dynamic modulus at an oscillatory frequency of $1 \mathrm{~Hz}$, and (b-d) photographs at $55^{\circ} \mathrm{C}$ for toluene/C18AA/water emulsion with various chlorides.

\subsection{Gelation concentration in the continuous aqueous phase}

The gelation of the C18AA emulsion was affected by the concentration of C18AA and salts. Based on the proposed mechanism of C18AA emulsion gel formation (Scheme 1), the gelation behavior could be normalized with the C18AA concentration in the continuous aqueous phase $[\mathrm{C} 18 \mathrm{AA}]_{\mathrm{w}}$.

The C18AA distribution coefficient $\phi_{\mathrm{W}}$ in the toluene/ water systems were examined at the concentration of 0.1 $\mathrm{M}$ for various chloride salts (Fig. 6a). From the figure, it is clear that $\phi_{\mathrm{W}}$ without salt was $\sim 40 \%$ below $40^{\circ} \mathrm{C}$, and it slightly increased to $50 \%$ at $55^{\circ} \mathrm{C}$. Interestingly, in the presence of chlorides, $\phi_{\mathrm{W}}$ at any temperature was higher than that in the absence of salts, and increased according to the Hofmeister series order. Finally, $\phi_{\mathrm{W}}$ in $0.1 \mathrm{M} \mathrm{LiCl}$ reached $\sim 90 \%$ at $55^{\circ} \mathrm{C}$, which means that $[\mathrm{C} 18 \mathrm{AA}]_{\mathrm{w}}$ at $55^{\circ} \mathrm{C}$ became 1.8 -fold of that at $25^{\circ} \mathrm{C}$ by hydration. Worthy to note, the distribution in the toluene phase was almost $0 \%$ at each conditions, namely C18AA transferred from $\mathrm{O} /$ $\mathrm{W}$ interface to water phase by hydration.

Based on $\phi_{\mathrm{W}}$ at viscosity transition points, the values of [C18AA]were converted to that in the aqueous phase, $[\mathrm{C} 18 \mathrm{AA}]_{\mathrm{w}}$. Figure $6 \mathrm{~b}$ shows the phase diagram where $[\mathrm{C} 18 \mathrm{AA}]_{\mathrm{w}}$ of the C18AA emulsion was plotted for various transition temperatures. Below $45^{\circ} \mathrm{C},[\mathrm{C} 18 \mathrm{AA}]_{\mathrm{w}}$ should be $16.5 \mathrm{wt} \%$ for gelation. The threshold value of $[\mathrm{C} 18 \mathrm{AA}]_{\mathrm{w}}$ was independent of the additional salts, and the concentration of $16.5 \mathrm{wt} \%$ was equal to the overlap concentration of the elongated micelles ${ }^{18)}$. This is in good agreement with the former assumption that a C18AA emulsion gel was formed with a micellar network comprising a continuous aqueous phase (Scheme 2a). At lowered [C18AA] and/or lowered temperature, addition of salt could help increase both $[\mathrm{C} 18 \mathrm{AA}]_{\mathrm{w}}$ and gelation.

However, above $45^{\circ} \mathrm{C}$, the gelation was affected not by $[\mathrm{C} 18 \mathrm{AA}]_{\mathrm{w}}$, but by temperature. This was related to the transition of the C18AA micellar property, so that the elon- 
(a)

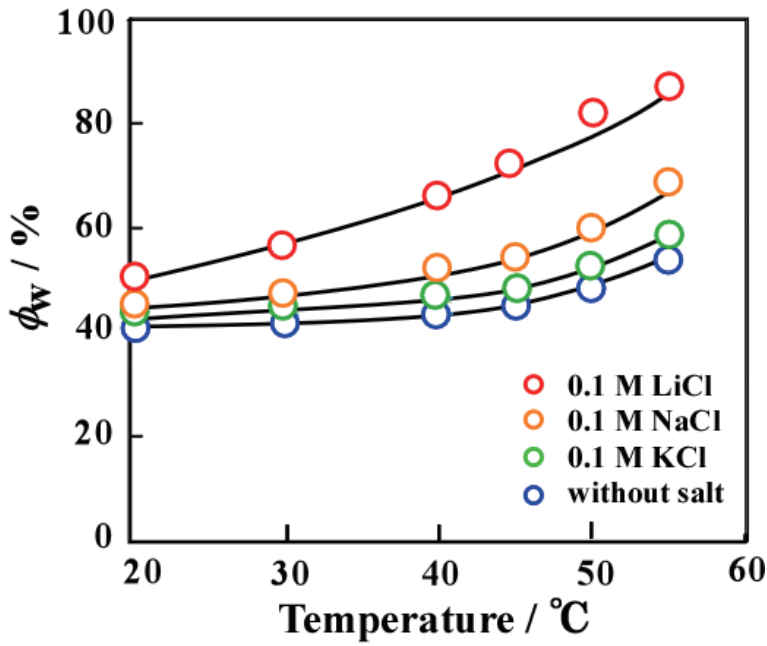

(b)

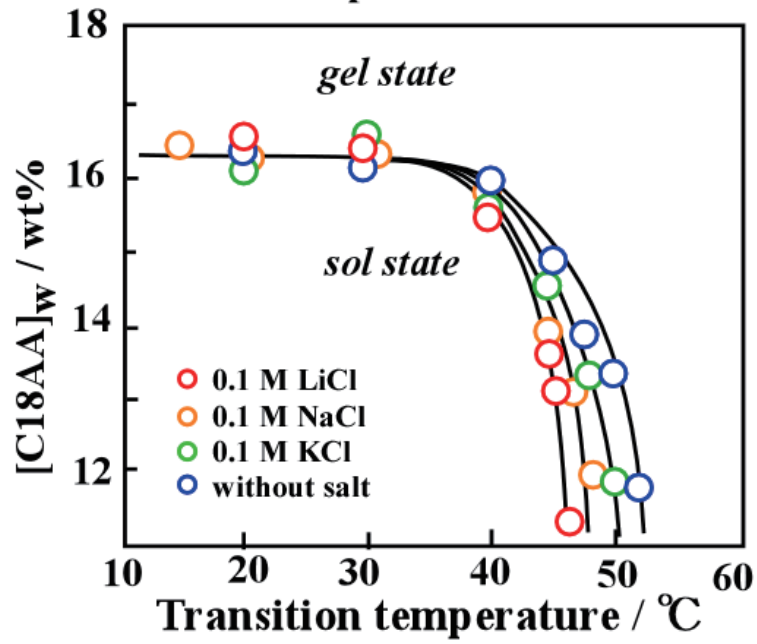

Fig. 6 (a) Temperature dependence of distribution coefficient of C18AA in the toluene/water system with various chlorides. (b) Phase diagram of the toluene/C18AA/water emulsion.

gated C18AA micelles entangled and their solution showed highly viscoelastic property above $42^{\circ} \mathrm{C}$ with $\mathrm{LiCl}$ and above $48^{\circ} \mathrm{C}$ without salt ${ }^{18)}$. It seemed that the viscosity of
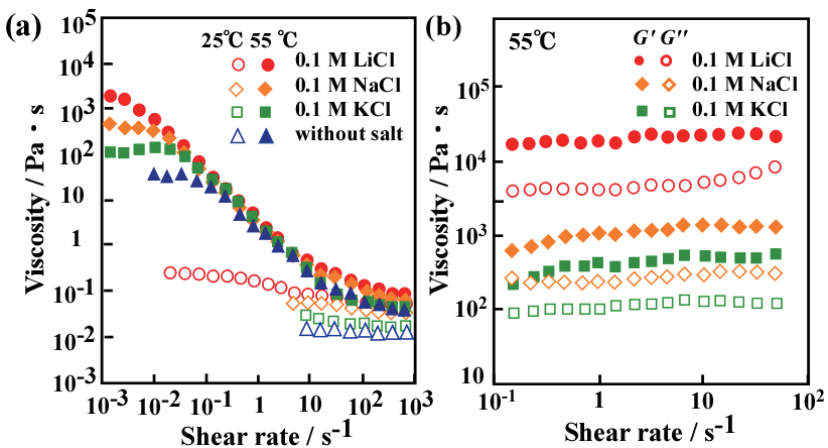

Fig. 7 (a) Steady shear viscosity at $25^{\circ} \mathrm{C}$ and $55^{\circ} \mathrm{C}$, and (b) dynamic rheology at $55^{\circ} \mathrm{C}$ of the toluene/C18AA/ water emulsion. [C18AA] $=23 \mathrm{wt} \%$.

the C18AA emulsion increased above $\sim 45^{\circ} \mathrm{C}$, regardless of $[\mathrm{C} 18 \mathrm{AA}]_{\mathrm{w}}$, because of the micellar entanglement in the continuous aqueous phase (Scheme $2 \mathrm{~b}$ and $\mathrm{c}$ ).

Gelation of C18AA emulsions was dominated by C18AA micelles in the continuous aqueous phase, i.e., the C18AA micellar network in the aqueous phase was necessary for the formation of a C18AA emulsion gel. Figure $7 \mathrm{a}$ shows the steady shear viscosity of 23 wt \%-C18AA emulsion gels. The zero-shear viscosity of the emulsions in the presence of chlorides increased according to the cation size at $55^{\circ} \mathrm{C}$, indicating that a higher $[\mathrm{C} 18 \mathrm{AA}]_{\mathrm{w}}$ value increases the viscosity of the emulsion because of a denser micellar network. Interestingly, the rheological properties of the emulsions differ slightly from that of the original C18AA micellar solution. In our previous work ${ }^{18)}$, the dynamic rheology of a C18AA aqueous solution at $52^{\circ} \mathrm{C}$ showed the Maxwell model ${ }^{29)}$ because of the entanglement of wormlike micelles. In the present study, the C18AA emulsion gels at $52^{\circ} \mathrm{C}$ showed frequency-independent gel-like behavior, in which the elastic modulus $G$ ' exceeded the viscous modulus $G$ " at any frequency ${ }^{9,30}$. This implied that the emulsion systems also added to the gel strength of C18AA micellar networks. It seemed that dispersed droplets also contributed to the emulsion gel network.

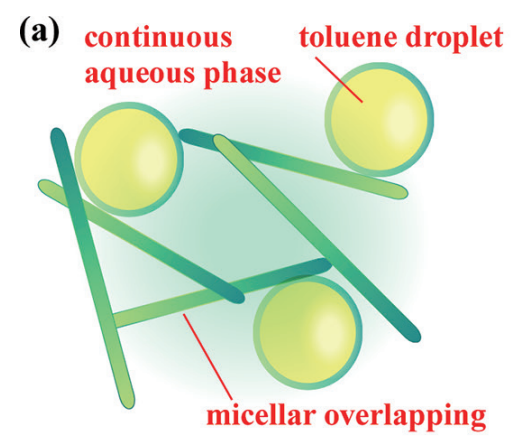

$[\mathrm{C} 18 \mathrm{AA}] \mathrm{w}>16.5 \mathrm{wt} \%$ $\mathrm{T}<45^{\circ} \mathrm{C}$ (b)

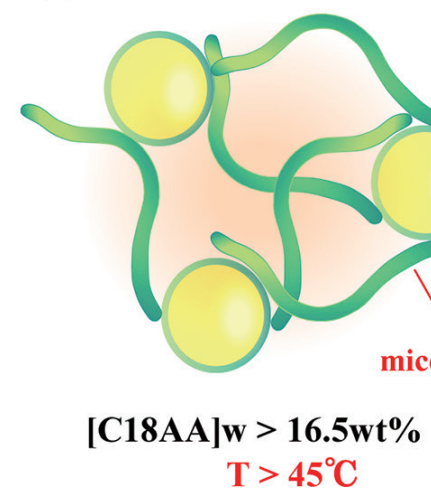

(c)

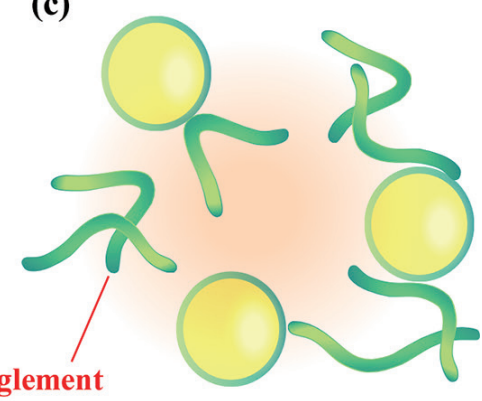

[C18AA]w $<16.5 w t \%$

Scheme 2 Gel structure of C18AA emulsions for various $[\mathrm{C} 18 \mathrm{AA}]_{\mathrm{w}}$ and temperature values. 


\section{M.-Imura, Y. Imura and T. Kawai}

\section{CONCLUSION}

Gelation of C18AA emulsions was observed under conditions that formed C18AA micellar networks in the continuous aqueous phase. Increasing the C18AA concentration in the aqueous phase could simply help the micellar network grow, and gelled the emulsion above the concentration of $16.5 \mathrm{wt} \%$. It was found that the viscosity of a C18AA emulsion increased on the addition of chloride because of the salting-in effect, which promotes the distribution of C18AA in the continuous aqueous phase. Furthermore, viscosity transition was also induced by heating owing to micellar elongation and micellar entanglement above $45^{\circ} \mathrm{C}$. These emulsion gel systems indicate the advances in the development of self-assembled gel fibrils such as amino acid-based supramolecules, bio-polymers, and worm-like micelles toward achieving emulsions with sufficient strength and stimuli-responsive behavior.

\section{References}

1) Esser-Kahn, A.P.; Odom, S.A.; Sottos, N.R.; White, S.R.; Moore, J.S. Triggered release from polymer capsules. Macromolecules 44, 5539-5553(2011).

2) Nuruzzaman, M.; Rahman, M.M.; Liu, Y.; Naidu, R. Nanoencapsulation, nano-guard for pesticides: a new window for safe application. J. Agric. Food Chem. 64, 1447-1483 (2016).

3) Song, Y.; Chan, Y.K.; Ma, Q.; Liu, Z.; Shum, H.C. Allaqueous electrosprayed emulsion for templated fabrication of cytocompatible microcapsules. ACS Appl. Mater. Interfaces 7, 13925-13933 (2015).

4) Chiu, Y.-L.; Chan, H.F.; Phua, K.K.L.; Zhang, Y.; Juul, S.; Knudsen, B.R.; Ho, Y.-P.; Leong, K.W. Synthesis of fluorosurfactants for emulsion-based biological applications. ACS Nano 8, 3913-3920 (2014).

5) Takahashi, Y.; Fukuyasu, K.; Horiuchi, T.; Kondo, Y.; Stroeve, P. Photoinduced demulsification of emulsions using a photoresponsive gemini surfactant. Langmuir 30, 41-47 (2014).

6) Takahashi, Y.; Koizumi, N.; Kondo, Y. Active demulsification of photoresponsive emulsions using cationicanionic surfactant mixtures. Langmuir 32, 683-688 (2016).

7) Uyama, M.; Ikuta, K.; Teshigawara, T.; Watanabe, K.; Miyahara, R. The viscosity stability of O/W emulsion containing \&alpha;-gel through an ionic-complex system. J. Oleo Sci. 62, 9-16(2013).

8) Marquardt, D.; Sucker, H. Oil-in-water-emulsion gels: determination and mathematical treatment of flow properties. Eur. J. Pharm. Biopharm. 46, 115-124 (1998).

9) Vianna-Filho, R.P.; Petkowicz, C.L.O.; Silveira, J.L.M. Rheological characterization of $\mathrm{O} / \mathrm{W}$ emulsions incor- porated with neutral and charged polysaccharides. Carbohydr. Polym. 93, 266-272 (2013).

10) Peng, J.; Simon, J.R.; Venema, P.; van der Linden, E. Protein Fibrils Induce Emulsion Stabilization. Langmuir 32, 2164-2174(2016).

11) Suzuki, T.; Takei, H.; Yamazaki, S. Formation of fine three-phase emulsions by the liquid crystal emulsification method with arginine $\beta$-branched monoalkyl phosphate. J. Colloid Interface Sci. 129, 491-500 (1989).

12) Alam, M.M.; Aramaki, K. Hexagonal phase based gelemulsion ( $\mathrm{O} / \mathrm{H} 1$ gel-emulsion) : formation and rheology. Langmuir 24, 12253-12259 (2008).

13) May, A.; Aramaki, K.; Gutiérrez, J.M. Phase behavior and rheological analysis of reverse liquid crystals and W/I2 and W/H2 gel emulsions using an amphiphilic block copolymer. Langmuir 27, 2286-2298(2011) .

14) Esquena, J.; Nestor, J.; Vílchez, A.; Aramaki, K.; Solans, C. Preparation of mesoporous/macroporous materials in highly concentrated emulsions based on $\mathrm{cu}-$ bic phases by a single-step method. Langmuir 28, 12334-12340 (2012).

15) Aramaki, K.; Kabir, M.H.; Nakamura, N.; Kunieda, H.; Ishitobi, M. Formation of cubic-phase microemulsions in sucrose alkanoate systems. Colloids Surf. A 183185, 371-379 (2001).

16) Morita, C.; Sugimoto, H.; Matsue, K.; Kondo, T.; Imura, Y.; Kawai, T. Changes in viscosity behavior from a normal organogelator to a heat-induced gelator for a longchain amidoamine derivative. Chem. Commun. 46, 7969-71 (2010).

17) Morita, C.; Sugimoto, H.; Imura, Y.; Kawai, T. Doublestimuli responsive O/W emulsion gel based on a novel amidoamine surfactant. J. Oleo Sci. 60, 557-562 (2011).

18) Morita, C.; Imura, Y.; Ogawa, T.; Kurata, H.; Kawai, T. Thermal-sensitive viscosity transition of elongated micelles induced by breaking intermolecular hydrogen bonding of amide groups. Langmuir 29, 5450-5456 (2013).

19) Coulombeau, H.; Testard, F.; Zemb, T.; Larpent, C. Effect of recognized and unrecognized salt on the selfassembly of new thermosensitive metal-chelating surfactants. Langmuir 20, 4840-4850 (2004).

20) Von Hippel, P.H.; Peticolas, V.; Schack, L.; Karlson, L. Model studies on the effects of neutral salts on the conformational stability of biological macromolecules. I. Ion binding to polyacrylamide and polystyrene columns. Biochemistry 12, 1256-1264(1973).

21) Baldwin, R.L. How Hofmeister ion interactions affect protein stability. Biophys. J. 71, 2056-2063(1996).

22) Pegram, L.M.; Record, M.T. Thermodynamic origin of Hofmeister ion effects. J. Phys. Chem. B 112, 94289436 (2008). 
23) Nandi, P.K.; Robinson, D.R. Effects of salts on the free energy of the peptide group. J. Am. Chem. Soc. 94, 1299-1308(1972).

24) Cao, M.; Wang, Y.; Ge, X.; Cao, C.; Wang, J.; Xu, H.; Xia, D.; Zhao, X.; Lu, J.R. Effects of anions on nanostructuring of cationic amphiphilic peptides. J. Phys. Chem. B 115, 11862-11871 (2011).

25) Lo Nostro, P.; Ninham, B.W. Hofmeister phenomena: an update on ion specificity in biology. Chem. Rev. 112, 2286-2322 (2012).

26) Kunieda, H.; Fukui, Y.; Uchiyama, H.; Solans, C. Spontaneous formation of highly concentrated water-in-oil emulsions (gel-emulsions). Langmuir 12, 2136-2140 (1996).
27) Vílchez, S.; Pérez-Carrillo, L.A.; Miras, J.; Solans, C.; Esquena, J. Oil-in-alcohol highly concentrated emulsions as templates for the preparation of macroporous materials. Langmuir 28, 7614-7621 (2012).

28) Coussot, P. Rheophysics: Matter in All Its States. Springer International Publishing (2014).

29) Acharya, D.P.; Kunieda, H. Wormlike micelles in mixed surfactant solutions. Adv. Colloid Interface Sci. 123126, 401-413 (2006).

30) Pal, A.; Srivastava, A.; Bhattacharya, S. Role of capping ligands on the nanoparticles in the modulation of properties of a hybrid matrix of nanoparticles in a 2D film and in a supramolecular organogel. Chem. Eur. J. 15, 9169-9182(2009). 